\title{
Aliadofilia y neutralidad de La Voz de Galicia en los años de la Primera Guerra Mundial
}

\author{
Mercedes ROMÁN PORTAS \\ Universidad de Vigo \\ mroman@uvigo.es
}

Recibido: 7 de diciembre de 2012

Aceptado: 10 de junio de 2013

\section{Resumen}

Este artículo trata de analizar la postura del diario regional La Voz de Galicia durante los años de la Primera Guerra Mundial. Cuando se inició la Guerra, la postura oficial de España, con Eduardo Dato en el gobierno, fue la neutralidad. Los periódicos, al igual que los políticos, respetaban esta decisión porque además de conveniente era una postura inevitable. A partir de agosto de 1914 la atención principal de La Voz de Galicia se dirigió a informar sobre la guerra, fue durante muchos meses el único tema de la primera plana. Aunque $L a$ Voz se declarase neutral, a través de los artículos publicados se podía observar desde el principio su aliadofilia.

Palabras clave: Primera Guerra Mundial; neutralidad; aliadofilia; germanofilia; censura.

\section{Aliadofilia and neutrality of La Voz de Galicia in the years of the First World War}

\begin{abstract}
This article tries to analyze the position of the newspaper during the years of First World War. When the World War began, the official position of Spain with Dato on power was neutrality. The newspapers, like politicians, respected this decision of the government because besides convenient it was an inevitable posture. Since August 1914 the main focus of La Voz de Galicia went to report on the war, which was for many months the only subject on the front page. Though $L a V o z$ was declared neutral, through the published articles it could be seen from the beginning its affiliation with the allies.
\end{abstract}

Keywords: World War; neutrality; aliadofilia; germanofilia; censorship.

\section{Referencia normalizada}

Román Portas, M. (2013) Aliadofilia y neutralidad en La Voz de Galicia en los años de la Primera Guerra Mundial. Historia y Comunicación Social. Vol. 18, págs. 293-303.

Sumario: 1. Introducción. 2. El entorno político del diario. 3. Postura de La Voz de Galicia durante la Primera Guerra Mundial. 4. Censura oficial y Censura roja. 5. Conclusiones. 6. Bibliografía 


\section{Introducción}

La Voz de Galicia, diario regional de A Coruña, salió a la calle por primera vez el 4 de enero de 1882. Nació como diario político para la defensa y propagación de los ideales políticos del Partido Democrático Progresista (republicano) pero fue evolucionando hacia un diario primordialmente informativo, pudiendo señalarse como línea divisoria el año 1910, en que su empresa se convirtió en Sociedad Anónima. A partir del año 1896 La Voz sería portavoz del partido liberal. Hasta la muerte en 1912 de Juan Fernández Latorre, fundador del diario, la evolución política del diario fue consecuencia de la carrera política de su fundador. Desde entonces la evolución de $L a$ Voz de Galicia fue consecuencia de las ideas políticas y de los intereses de las personas que constituyeron el consejo de gobierno y administración de su empresa editora.

Para la realización de esta investigación se han revisado todos los números de $L a$ Voz desde 1910 hasta 1920 y las actas del Consejo de Administración de ese período fuente primaria de este trabajo.

\section{El entorno político del diario}

El 14 de marzo 1912 fallecía en Madrid el fundador de La Voz de Galicia, Juan Fernández Latorre. Era desde 1910 diputado a Cortes por A Coruña y desde 1911 gobernador civil de Madrid. A la muerte del fundador, su cuñado José María Ozores de Prado fue nombrado presidente del consejo de administración de La Voz de Galicia S.A.

En esos años formaba Gobierno el Partido Liberal con Canalejas. Fernández Latorre iba de la mano de García Prieto, marqués de Alhucemas, que en esos momentos era ministro de Estado. El 14 de noviembre de 1912 Canalejas fue asesinado por el anarquista Manuel Pardiñas y dos días después fue nombrado jefe de Gobierno el conde de Romanones.

En 1913 se hacía visible la escisión en el Partido Liberal, con el manifiesto de los liberales demócratas seguidores de Montero Ríos y García Prieto en el que declaraban su distancia con Romanones. La Voz de Galicia del 26 de junio de 1913 se mostraba de acuerdo con la disidencia y a favor del marqués de Alhucemas que pasó a liderar el Partido Liberal Democrático.

En aquella política del turnismo, en octubre de 1913 el rey Alfonso XIII llamó al conservador Dato para encargarle la formación del gobierno. Dato convocó elecciones a Cortes en marzo de 1914 en las que José María Ozores de Prado sería elegido como diputado por A Coruña.

Durante la Primera Guerra Mundial, en diciembre de 1915 cayó el gobierno Dato y le sucedió Romanones. Su gobierno vivió un período de intensa agitación política y económica producido en buena parte por la guerra. 


\section{Postura de $L a V o z$ de Galicia durante la Primera Guerra Mundial}

Cuando se inició la Guerra Mundial, la postura oficial de España con Dato en el poder fue la neutralidad. Los periódicos, al igual que los políticos, respetaban esta decisión del gobierno porque además de conveniente era una postura inevitable. A partir de agosto de 1914 la atención principal de La Voz se dirigió a informar sobre la guerra, fue durante muchos meses el único tema de la primera plana, con artículos que resumían los acontecimientos y sobre todo con información telegráfica. Cada día aparecía un grabado bajo el título "Figuras de la guerra", en el que se daba a conocer distintos personajes de los bandos beligerantes.

Aunque $L a V o z$ se declarase neutral, a través de los artículos publicados se podía observar desde el principio su aliadofilia. En un editorial del 8 de agosto decía que el caso de Alemania era un caso de locura sublime al enfrentarse contra casi todas las potencias europeas, incluso se atrevía a adelantar el fin "Con la derrota de Alemania que lógicamente pensando es de esperar, ya se apunta por todas partes la quiebra del imperialismo a impulsos de la democracia."

En años anteriores había en el diario las secciones "La Voz en París", "La Voz en Berlín", "La Voz en Londres", ciudades desde las que los corresponsales enviaban sus colaboraciones. Al estallar el conflicto, dejó de aparecer en las páginas del diario la sección "La Voz de Berlín", mientras que las otras dos aparecieron prácticamente a diario. Desde París enviaba sus artículos Bartolomé Calderón, los de Londres estaban firmados por John X. Los artículos de los corresponsales de La Voz despertaron interés hasta el punto que el 18 de octubre de 1914 decía en sus páginas:

"Varios colegas de provincias y de Madrid vienen reproduciendo o glosando, entre otros originales de interés que en $L a V o z$ ven la luz, las interesantes crónicas que acerca de la guerra actual nos envía desde París nuestro distinguido y cultísimo colaborador D. Bartolomé Calderón (...). Agradecidos por el tijereteo, aunque no citen la procedencia."

Cuando a los pocos días de estallar la guerra, comenzaron a marcarse tendencias determinadas en la prensa madrileña, respecto a la postura que España debía mantener, $L a V o z$ publicó un artículo el 22 de agosto, en el que defendía la neutralidad; comentaba, entre otras cosas, el famoso artículo publicado por Diario Universal "Neutralidades que matan", que firmado por "equis" se atribuía a Romanones; $L a$ $V o z$, después de comentar la posición de Lerroux y de los republicanos, terminaba al artículo diciendo:

"Respecto a los monárquicos, véase la actitud del Gobierno, la de los liberales demócratas explícitamente manifestada por el Sr. García Prieto, y la de elementos conservadores de las diversas ramas. En más de las dos terceras partes del campo de la política española no germinará la simiente bélica que lanzaron a boleo el $\mathrm{Sr}$. Lerroux primero y el conde de Romanones por último. Eso es lo primero. Lo otro quizás fuese una desgracia." 
Bartolomé Calderón, en los artículos que enviaba desde París no ocultaba que era francófilo. El 2 de septiembre, comentando la actitud de Italia y España decía explícitamente:

"En cuanto a España, los franceses no han dudado un momento de nuestra neutralidad y de nuestra simpatía. Una buena parte de la opinión pública contaba con algo más y ha sufrido una tremenda decepción cuando ha visto que la prensa española y los españoles en general no parecían tomar partido en la contienda. El asombro ha sido mayor todavía después del atentado alemán contra Bélgica y la actitud resuelta de Inglaterra."

El corresponsal de $L a V o z$ era de la opinión de que España no podía permanecer indiferente y que una actitud neutral concluiría forzosamente por resultar un acto de enemistad contra Francia, Inglaterra y Portugal que podía costarle caro. Y añadía:

"A mi juicio, es preciso que España movilice inmediatamente todas las fuerzas de que pueda disponer, organice un ejército lo mejor y más pronto posible y esté lista para defender sus intereses en un momento que puede no hacerse esperar."

Días después $L a$ Voz agradecía que el cónsul inglés en La Coruña le hubiese hecho llegar un ejemplar de la "Correspondencia referente a la crisis europea" y otro de "Afirmaciones del ministro de Estado inglés, sir Edward Grey" que habían sido presentados en la Cámara de los comunes en los primeros días de agosto y comentaba que eran muy interesantes para juzgar los orígenes de la contienda desatada en Europa.

Ese mismo día, 5 de septiembre, $L a$ Voz insertó el telegrama que desde la Diputación de La Coruña se había enviado al presidente del consejo de ministros apoyando su postura neutral. Estaba firmado por el vicepresidente de la comisión provincial de la Diputación Manuel Sandomingo (que formaba parte del consejo de gobierno de La Voz de Galicia) y por el secretario Manuel Viturro.

Desde el estallido de las hostilidades, la guerra militar se dobló con la propagandística; los dos bandos necesitaban atraer a su causa a los países neutrales. Alemania hizo depender su propaganda del Gran Cuartel General y del Ministerio de Asuntos Exteriores y la entregó a militares y diplomáticos, poco expertos en su utilización. Los aliados poseían la agencia francesa Havas y la británica Reuters. El 2 de octubre de 1914 un artículo de $L a$ Voz decía que había recibido un buen número de periódicos del resto de España que revelaban que desde el principio de la guerra la opinión pública del país había bebido en fuentes alemanas y volvía a publicar, el 18 de octubre la preocupación de Bartolomé Calderón por la tendencia de parte de la prensa española a favor de los alemanes:

"No dudéis que lo mismo en Francia e Inglaterra que en Bélgica se conoce hasta el último detalle de la campaña injuriosa contra los aliados que los alemanes han librado en una parte de los periódicos de España. Os aseguro que he visto por mis propios ojos en cierto lugar, en París, al lado de algún periódico suizo y holandés, las colecciones del $A B C$, La Tribuna, El Imparcial (con ciertos artículos marcados al lápiz azul) y los demás diarios de Madrid y provincias que forman un enorme paquete, 
más voluminoso todavía que el de los periódicos turcos, que es la sola prensa del mundo que se distingue por su simpatía por los invasores y destructores del pueblo belga. Por las agencias de publicidad, entre otros medios, se conoce perfectamente la campaña injusta de una parte de la prensa española contra Francia, Inglaterra, etc."

A lo largo de 1915 la información sobre la guerra pasó por lo general a segunda plana. En abril, La Voz reprodujo las declaraciones de Romanones a un periódico inglés, que publicó Diario Universal, en las que se mostró cauteloso y prudente, además de negar cualquier complicación material o espiritual en el artículo "Neutralidades que matan". La Voz comentaba el 9 de abril de 1915 "En realidad las circunstancias más están para mostrarse cautelosos que para desentonar con salidas de tono que arriesgarían mucho a quien incurriese en ellas durante estos días de manifiesto recelo e inestabilidad de la opinión."

Por entonces se había desatado en la prensa española una auténtica campaña, a favor o en contra de uno de los dos bandos, lo cual reflejaba la manera de opinar de los lectores de cada uno; a La Voz le parecía imposible no inclinarse por uno de los bandos, pero decía: "El sustentar cualquiera de esas filias no debiera justificar las fobias". Opinaba el 16 de mayo que era una imprudencia las notas o impresiones tendenciosas que publicaban algunos periódicos, ya que no respetaban la neutralidad:

"Tienen consecuencias demasiado graves, estas conversaciones de los desocupados, para alentarlas con la publicidad. Nosotros hemos recibido a diario, noticias e informaciones que estimamos indiscretas y hemos preferido guardar un prudente silencio"

El 6 de junio de 1915 La Voz alabó la actitud del marqués de Alhucemas, que defendía una y otra vez la neutralidad estricta, demostraban sus declaraciones que Romanones no podía hablar en nombre de las dos ramas del Partido Liberal:

"El marqués de Alhucemas, creyendo, y creyendo bien, que se inspira en una verdadera ansia patriótica, rompe con todo convencionalismo, preconiza la neutralidad inquebrantable, sin frase, sin interpretaciones ni distingos, la neutralidad, que no admite confabulación con nadie ni soporta mezcla de política alguna.”

En ese mismo mes por iniciativa de $A B C$ se formó un bloque periodístico, que trataba de apoyar y defender la neutralidad; en pocas semanas se adhirieron más de 160 publicaciones de Madrid y provincias, pero eso no significaba que esos periódicos no tuviesen inclinación o simpatía hacia alguno de los bandos (Iglesias, 1980: 110).

El 8 de diciembre Romanones sucedía a Dato en la presidencia del gobierno, las dos ramas de los liberales aparecían de nuevo unidas y $L a$ Voz, el 15 de ese mes explicaba cómo se había llegado a la unión. Según García Prieto se consiguió una coincidencia de criterios tanto en la política interior como en la exterior. En la internacional una neutralidad estricta; en la interior un gobierno parlamentario; se prometía estar el mayor tiempo posible en contacto con el Parlamento, manteniendo las Cortes abiertas. 
Durante 1915 los países beligerantes empezaron a sentir la necesidad de asegurar la simpatía de sus partidarios en la prensa española con subvenciones económicas a los periódicos. Los germanos y austríacos hicieron retirar a las firmas que tenían conexión con ellos, los anuncios de los periódicos aliadófilos; y los aliados hicieron otro tanto. Como señala Enrique Montero "El hecho es que a partir de principios de 1916 se desarrolla en España una guerra de propaganda de gigantesca magnitud y moderna sofisticación. El dinero invade el mundo periodístico en grandes cantidades" (Montero: 1983, 245-246).

El 8 de febrero $L a$ Voz insertó un artículo de Pérez Lugín en el que comentaba el episodio entre Luis Araquistain, redactor de El Liberal y Torcuato Luca de Tena, por el artículo que aquél escribió en The Daily News, animando entre otras cosas a los ingleses a que se anunciasen en periódicos españoles (Iglesias, 1980: 110-111).

En febrero de 1916 se nombró a John Walter para dirigir la propaganda británica en España. Como presidente de la junta de directores de The Times, su nombramiento indicaba claramente la importancia que el Foreign Office quería dar a la propaganda en España. En mayo de 1916 Walter estableció la Agencia Anglo-Ibérica donde centralizó la propaganda (Montero, 1983: 249). En septiembre La Voz hacía referencia a la lista negra inglesa: "El hecho es que en gran parte de España la neutralidad espiritual, y en algunos puntos material, no se ha guardado tan estrictamente como fuera necesario. La famosa lista negra inglesa no tendría razón de existir, si ello no aconteciese así." Francisco Iglesias recogió unas palabras de $A B C$ en las que dice cómo afectó este tema al diario madrileño: "Perdemos por ser neutrales, por servir a España, más de trescientas mil pesetas al año. La demostración es sencilla, han perseguido a nuestros anunciantes con amenaza de incluirlos en las listas negras si continuaban haciendo su publicidad en nuestras columnas, y las bajas que por esta coacción experimentamos exceden de la cifra que queda anotada" (Iglesias, 1980: 166).

Con la entrada de los Estados Unidos en la guerra, en febrero de 1917, la información sobre la contienda volvió a ocupar en $L a$ Voz la primera plana. Fue otro momento peligroso para el mantenimiento de la neutralidad española. El 29 de marzo La Gaceta publicó un Real Decreto suspendiendo las garantías constitucionales e implantando la consiguiente censura previa de los periódicos. Romanones trataba de impedir principalmente la propaganda e información relativas a las huelgas, movimientos de tropas y de algunos problemas diplomáticos; pero dimitió el 19 de abril al no compartir la mayoría su deseo intervencionista (Gómez, 1981: 467); le sucedió García Prieto, gracias a lo cual se salvó la neutralidad, como ya resaltaba La Voz al dar la noticia del cambio el día 20.

Al día siguiente cesaba la suspensión de las garantías constitucionales. Pero su gobierno no llegó a durar dos meses, dimitió el 10 de junio de ese año en relación con las Juntas de defensa (cfr. Redondo: 1970, 33 y siguientes). Le sucedió Dato, que se apresuró a acentuar las medidas represivas, especialmente en materia de prensa. El 25 de junio se suspendieron de nuevo las garantías constitucionales y se estableció 
la censura previa. Después de los sucesos del verano de 1917, Dato dimitió el 27 de octubre siendo sustituido de nuevo por García Prieto que formó un gobierno de concentración (Barreiro, 1986, 402-403).

Cuando el 19 de marzo de 1918 dimitió el ministro de la Cierva hubo crisis total de Gobierno y a García Prieto le sucedió Maura con un Gobierno Nacional. Se presentó a las Cortes el proyecto de ley de represión del espionaje; fue combatida por casi todos los periódicos; La Voz de Galicia aunque no dio su opinión sobre el asunto, recogió la polémica en su sección telegráfica. La ley fue aprobada el 7 de julio. A pesar de todo, la neutralidad española volvió a verse en peligro al continuar el hundimiento de barcos españoles por los alemanes, en agosto de aquel año. En el Consejo de ministros celebrado el 8 y 9 de agosto, se acordó enviar una nota a Alemania; la prensa no tuvo noticia hasta el 20 de ese mes para dar tiempo a que Alemania la hubiese recibido; a partir de entonces el gobierno implantó una severa censura de prensa.

En octubre de 1918 empezaba a vislumbrarse la paz. El 6 de noviembre dimitía Maura al no conseguir la aprobación de los presupuestos, y le sucedió García Prieto, cuyo Ministerio no llegó a gobernar ni un mes; el 5 de diciembre Romanones formó Gobierno.

El 10 de enero de 1919 Alemania firmó el tratado de paz de París, y el 28 de junio, en el quinto aniversario del asesinato de Sarajevo, Alemania firmó el tratado de Versalles, por el que aceptó todas las exigencias que le fueron impuestas por las potencias vencedoras. $\mathrm{La} \mathrm{Voz}$ tituló durante ese tiempo la información sobre las conversaciones "En torno la paz". Parece significativo el artículo del 31 de enero de 1919 en el que anunciaba la vuelta de John Walter a su país:

"Durante los años de guerra, se ha dado a conocer intensamente en nuestra nación, gracias al brillo que supo prestarle, haciendo honor a su prosapia, John Walter. Todos los países agrupados en uno y otro bando de los beligerantes, han tenido establecidas oficinas montadas con la mayor seriedad en las naciones neutrales, con objeto de coordinar los elementos de propaganda, la distribución de noticias e informaciones, recogida de datos y sostenimiento de relaciones de varios órdenes entre los pueblos y las instituciones representados y las entidades y personas del país en que la oficina se instaló. Al frente de la oficina británica, Agencia anglo-ibérica, vino a España John Walter...y en ella desarrolló durante cuatro años una labor espléndida,(...) en una propaganda noble, apasionada, pero no agresiva."

Una vez terminada la guerra con la victoria de los aliados, La Voz sólo hizo referencia a la agencia Anglo-Ibérica, lo que hace suponer que estuvo relacionada con ella durante ese tiempo.

\section{Censura oficial y censura roja}

Ya se ha hecho referencia al Real Decreto del 29 de marzo de 1917 por el que se instauraba la censura previa a la prensa, como consecuencia de amenaza de una 
posible huelga general. Inmediatamente se reunieron los directores de periódicos madrileños para tratar el tema. El 1 de abril, La Voz informaba que la comisión que se había constituido en aquella reunión, había visitado al conde de Romanones para rogarle la supresión de la censura. Algunos periódicos consideraban que ésta no se aplicaba con justicia, por eso los directores de El Día, El Debate y La Acción visitaron a Romanones para quejarse de que la censura era benevolente con los periódicos partidarios de los aliados y sin embargo los trataba con rigor a ellos. La Voz del 17 de abril informaba:

"Dijo que a unos y a otros les prohibirá terminantemente que hagan campañas que puedan acarrear daño a la neutralidad de España... A El Liberal que no mandó las galeradas a la censura, se le impuso una multa de 125 pesetas. Dio seguridades el jefe del Gobierno de que se procederá con imparcialidad absoluta, pero que será inflexible en no tolerar ninguna nota estridente o tendenciosa en cuanto atañe a la cuestión internacional."

El 26 de junio, el gobernador civil de La Coruña se reunió con los directores de los periódicos locales: La Voz de Galicia, El Noroeste y El Ideal Gallego que había salido a la calle por primera vez en abril de ese año. Les habló de la necesidad de ejercer en la localidad una censura previa, además de la establecida en Madrid. Les exigía que cada periódico enviase las galeradas, lo que retrasaría la salida a la calle de los diarios. La Voz comentaba ese mismo día que el rigor de la censura era tan grande que a las tres de la madrugada apenas habían llegado telegramas ni llamadas telefónicas con noticias de lo que pasaba en el extranjero.

Los directores consiguieron cambiar la proposición del gobernador a cambio de llevar a la práctica las instrucciones que publicó $L a$ Voz al día siguiente:

"Instrucciones a que deberán sujetarse los señores directores de los periódicos La Voz de Galicia, El Noroeste y El Ideal Gallego de esta capital, durante la suspensión de garantías constitucionales acordada por Real decreto de fecha de ayer, para evitar que sean remitidas a este Gobierno las galeradas de sus periódicos, a previa censura: $1^{\mathrm{a}}$. No publicarán, en absoluto, nada contra las instituciones y disciplina militar, ni sobre actos o acuerdos militares, reales o supuestos, así como tampoco sobre resoluciones del Gobierno respecto a asuntos militares. $2^{\mathrm{a}}$ Tampoco publicarán nada referente a movimientos de tropas, ni de buques nacionales o extranjeros, ni noticias relativas a exportación a países beligerantes, ni tampoco noticias ni comentarios sobre huelgas. También se abstendrán, en absoluto, de publicar manifiestos, de cualquiera clase que fueren. $3^{\mathrm{a}}$ Tampoco publicarán comentarios sobre nombramientos o resoluciones del Gobierno en asuntos militares, ni comentarios ni juicios sobre operaciones de la guerra, como igualmente, juicio ni comentarios sobre la actitud de España con relación a la guerra internacional y a la neutralidad, ni nada contrario a los Soberanos o jefes de los Estados extranjeros, y $4^{\circ}$ En sus respectivos periódicos no aparecerán espacios en blanco, ni líneas tachadas, que pueda sobre entenderse que obedecen a previa censura."

La Voz al publicarlas decía que así los lectores comprenderían si esos días había alguna deficiencia informativa. Y con cierta ironía comentaba que con excepción de todo eso, se podía hablar de todo lo demás. El 7 de julio otro artículo enumeraba los temas que a causa de la previa censura, no podía tratar: cuestión militar, movimientos 
de tropas, juntas de defensa, manifiestos y proclamas societarias; mítines y huelgas; movimientos de buques de guerra; torpederos de barcos nacionales o extranjeros en aguas jurisdiccionales, etc.

En alguna ocasión La Voz de Galicia se quejó de que con motivo de la censura se perdía tiempo, esperando la llegada de telegramas que nunca llegaban, y dinero.

El 30 de julio se suprimió la censura previa con la condición de que los periódicos informasen mirando el interés de la Patria. Pero volvió a quedar restablecida: "Tras un breve respiro tornamos a las andadas. Volvemos a tener que escribir con falsilla supeditando nuestro criterio al del manejador del lápiz rojo." ( $\mathrm{La} \mathrm{Voz}, 9$ de agosto).

Ante el recrudecimiento de la vigilancia y control de las informaciones, en septiembre la Asociación de la Prensa de Madrid hizo una serie de peticiones a García Prieto, que era entonces el ministro de Gobernación, solicitando la total supresión de la censura (cfr. Redondo, 1970: 218)

En marzo de 1919, primero en Barcelona y después en Madrid y otras capitales españolas, el personal obrero de los talleres de la prensa, estableció la que se denominó censura roja. En Barcelona, estaba alentada por el Sindicato de Artes Gráficas, dependiente de la CNT. Los obreros se habían enfrentado a las empresas a raíz de la huelga de la Canadiense (cfr. Carr y Carr, 1981: 504). La censura roja que los obreros representantes del sindicato, ejercían en los periódicos pretendía eliminar informaciones contra los intereses de los obreros. En Madrid, la Asociación del Arte de Imprimir, controlada por UGT ordenó a sus asociados que en los periódicos no se imprimiesen noticias que atentasen contra las reivindicaciones obreras; era la respuesta a la censura oficial.

El 6 de abril $L a V o z$ insertó el siguiente telegrama:

"La censura roja. Barcelona sin prensa. Los periódicos estaban dispuestos a salir hoy, pero el acuerdo en tal sentido adoptado por las Empresas, hubo de ser suspendido de madrugada por haberse opuesto los cajistas de El Día a componer un suelto en que se hacía público que ya no se ejercería la censura roja. Circulada por teléfono la noticia a los periódicos barceloneses cuando estos estaban a punto de entrar en máquina, se reunieron los gerentes y acordaron que no se publicarán."

Las empresas periodísticas de Barcelona habían decidido suspender la publicación de sus periódicos mientras actuase la censura roja y adoptar la misma resolución ante cualquier imposición injusta de la clase obrera. Lo mismo decidieron los directores de los periódicos madrileños (cfr. Carr y Carr, 1981: 113). El 22 de marzo los carteros de Madrid y los de varias provincias declararon una huelga de brazos caídos como consecuencia el Gobierno estableció en toda España la suspensión de las garantías constitucionales. El 16 de abril La Voz volvía a quejarse de su incomunicación telegráfica y telefónica con el resto de España.

El 2 de mayo el Rey entregó a Maura el decreto de disolución de las Cortes y el $22 \mathrm{La} \mathrm{Voz}$ informaba de una circular del ministerio de Gobernación para que se autorizase la publicación de artículos, propaganda electoral, etc. sin censura previa. 
El 30 de junio un Real Decreto ponía fin a la censura de prensa. Dos días antes, en Versalles, se había firmado el tratado de paz con el que terminaba la Guerra Mundial.

\section{Conclusiones}

1. El diario regional La Voz de Galicia nació en 1882 como diario político, portavoz del Partido Democrático Progresista (republicano). Desde 1896 apoyaría al Partido Liberal. La evolución política del diario fue consecuencia de la carrera política de su fundador Juan Fernández Latorre. A su muerte la evolución política del periódico fue consecuencia de las ideas políticas de las personas del Consejo de Gobierno y Administración de la empresa editora.

2. Cuando murió Juan Fernández Latorre, fue nombrado presidente del Consejo de Administración de La Voz de Galicia SA, su cuñado José María Ozores de Prado. En marzo de 1914 fue elegido diputado a Cortes por La Coruña.

3. García Prieto, marqués de Alhucemas lideró una escisión del Partido Liberar del conde de Romanones, el Partido Liberal Democrático. La Voz de Galicia siempre defendió las posiciones de García Prieto.

4. Cuando se inició la Guerra Mundial, la postura oficial de España fue la neutralidad; postura que apoyó La Voz de Galicia por considerarla conveniente e inevitable. Pero en todas sus informaciones y opiniones se observaba su aliadofilia. Esto mismo sucedió con otros periódicos liberales, republicanos, reformistas y "de izquierda". Por ejemplo podemos citar a La Correspondencia de España, El País, El Imparcial, El Socialista, El Sol, La Mañana, entre otros. Los monárquicos liberales, mauristas, carlistas, etc. se posicionaron del lado de la autoridad y el orden establecido que a su juicio defendían los Imperios Centrales. Fue la posición defendida por El Debate, La Acción, ABC, La Tribuna, etc.

5. La aliadofilia se manifiesta desde el principio, ya el 8 de agosto un editorial de La Voz comentaba que el caso de Alemania era un caso de locura sublime al enfrentarse contra casi todas potencias europeas y adelantaba que con su lógica derrota ya se apuntaba por todas partes la quiebra del imperialismo a impulsos de la democracia. $A B C$ a pesar de defender la neutralidad fue acusado de germanófilo en diversas ocasiones. Una vez la acusación procedió del The Times de Londres, periódico que llegó a afirmar el 23 de septiembre de 1915, que $A B C$ estaba a favor de Alemania y que había sido fundado con dinero de la Allgemeine Electricitäs Gesellschaft, a lo que respondió el diario español en su número del 18 de ese mes.

6. En marzo de 1917 se instauró la censura previa a la prensa como consecuencia de una posible huelga general. En marzo de 1919 el personal obrero de los talleres de prensa estableció la que se denominó censura roja. En Barcelona estuvo alentada por el Sindicato de Artes Gráficas de la CNT y en Madrid por la Asociación del Arte de Imprimir controlada por UGT. Esta censura que pretendía eliminar informaciones contra los intereses de los obreros, afectó negativamente la economía de los periódi- 
cos y de La Voz. El 30 de junio un Real Decreto ponía fin a la censura de prensa. Dos días antes se había firmado en Versalles el tratado de paz con el terminaba la Guerra Mundial.

\section{Referencias Bibliográficas}

BARREIRO FERNÁNDEZ, J.R (1986): Historia de la ciudad de La Coruña. Ed. La Voz de Galicia: La Coruña

CARR, R. y CARR, S. (1981). "La crisis del parlamentarismo" en Varios Autores Historia General de España y América. Tomo XVI-2. Ed. Rialp: Madrid

COLECCIÓN DE LA VOZ DE GALICIA, desde 1 de enero de 1910 a 31 de diciembre de 1920

GÓMEZ APARICIO, P. (1981). Historia del periodismo español. Tomo III. Editora Nacional: Madrid

IGLESIAS FERNÁNDEZ, F. (1980) Historia de una empresa periodística. Prensa española. Editora de ABC y Blanco y Negro. Ed. Prensa Española: Madrid

LIBROS DE ACTAS, LA VOZ DE GALICIA S.A.-Consejo de Gobierno y Administración 1910-1920

MONTERO, E. (1983). "Luis Araquistain y la propaganda aliada durante la primera Guerra Mundial" en Estudios de Historia Social n 24-25. Ed. Instituto de estudios laborales y de la Seguridad Social: Madrid

REDONDO GÁLVEZ, G. (1970). Las empresas politicas de José Ortega y Gasset. El sol, Crisol, Luz (1917-1934). 2 tomos. Ed. Rialp: Madrid

\section{La autora}

Mercedes Román Portas es Profesora Titular de Universidad del área de periodismo (Universidad de Vigo: campus Pontevedra) desde el año 1998. Doctora en Ciencias de la Información por la Universidad de Navarra y Licenciada en Historia Moderna por la Universidad de Valladolid. Su principal área de docencia e investigación es la Teoría e Historia de la Comunicación. Ha dirigido 7 tesis doctorales en el ámbito de la Historia de la Comunicación y de la Teoría de la Comunicación. Coordina el Doctorado y el Máster Universitario en Investigación en Comunicación desde sus inicios en el año 2009. En este Máster imparte la materia: Estudio de los principales grupos de comunicación en España. Es directora de la sección departamental de Comunicación de la Universidad de Vigo. 